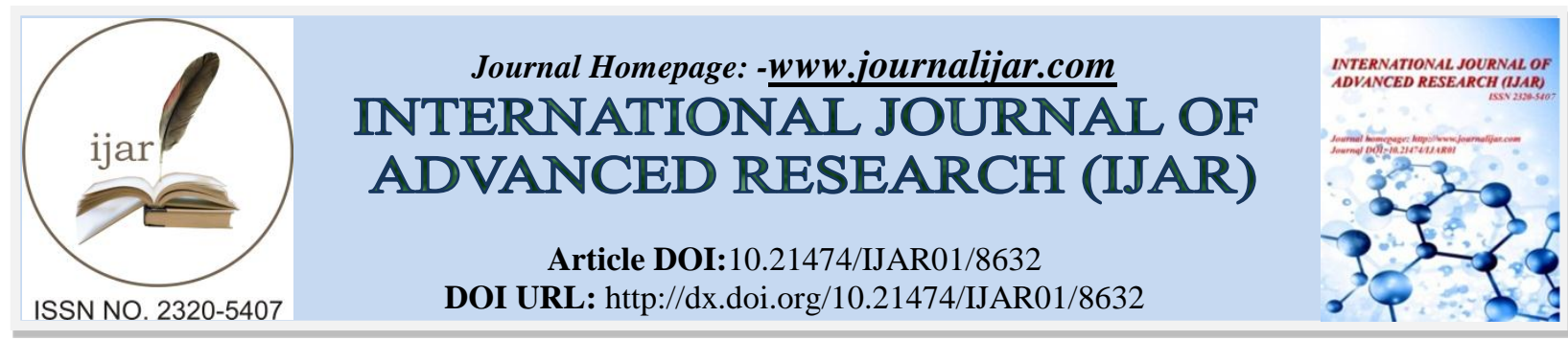

RESEARCH ARTICLE

\title{
STUDY OF SOME ESSENTIAL QUALITY CONTROL TEST PARAMETERS FOR THE PERFORMANCE OF DOSE CALIBRATORS IN NUCLEAR MEDICINE PRACTICES.
}

\section{A.K.M. Mizanur Rahman ${ }^{1}$, S. Reza ${ }^{2}$, Mahfuza Begum ${ }^{3}$, Mizanur Rahman $^{2}$, F. Reaz ${ }^{4}$, Mahbuba Begum ${ }^{1}$, R. Islam ${ }^{4}$, J. Ferdous ${ }^{1}$, S. Pervin ${ }^{1}$, M. M. M. Siraz ${ }^{1}$ and S. Yeasmin ${ }^{1}$.}

1. Health Physics Division, Atomic Energy Centre Dhaka, Bangladesh Atomic Energy Commission, 4 Kazi Nazrul Islam Avenue, Shahbag, Dhaka-1000, Bangladesh.

2. Institute of Nuclear Medicine and Allied Sciences, Dhaka Medical College Hospital Campus, Dhaka, Bangladesh.

3. Health Physics \& Radioactive Waste Management Unit, Institute of Nuclear Science and Technology, Atomic Energy Research Establishment, Bangladesh Atomic Energy Commission, Ganakbari, Savar, Dhaka, Bangladesh.

4. Department of Nuclear Engineering, University of Dhaka, Bangladesh.

\section{Manuscript Info}

\section{Manuscript History}

Received: 06 January 2018

Final Accepted: 08 February 2019

Published: March 2019

Key words:-

Nuclear medicine, Dose calibrator,

99mTc, Quality control.

\section{Abstract}

The aim of this study is to evaluate and compare the performance of two dose calibrators which are used in Nuclear Medicine Center by standard tests accuracy, constancy, linearity and geometry. To check the performance status of the dose calibrators the activity of radiopharmaceuticals must be accurately known before administered to the patients. Two dose calibrators of Institute Nuclear Medicine and Allied Sciences, Dhaka (Capintec, Inc.,Model no. CRC 25R and Veenstra, model no. VDC 404) performances were compared in accordance with varying geometry because most common measurement geometries utilized in clinical practice are glass vials, solid capsules and various types of plastic syringes. Vials and syringes filling volumes can be widely different, according to clinical needs. It was found that the measurement activity readings of one of these two dose calibrator, VDC-404, showed slightly deviating from accurate value because readings might be affected by the frequent change in background count. The results of the quality control (QC) tests revealed that the parameters that were traced for both dose calibrators were within the limits of the international standards, $\pm 5 \%$. Regular QC should cover precision, accuracy, linearity, and geometry of instrument, according to IAEA standards, e.g. (IAEA TECDOC-602 and 1599), that will guarantee to assure the proper practice of nuclear medicine diagnosis. It is also vital to fulfill radiation protection requirements as well as successful therapies and good quality image production in nuclear medicine practices. 


\section{Introduction:-}

In routine nuclear medicine practices different radionuclides (i.e. Tc-99m, F-18, I-131, Lu-177 etc.) are commonly used for both diagnostic and therapeutic purposes (Schrader et al., 2008) Accurate dose level must be known prior to administration of radiopharmaceuticals to the patients to fulfill radioprotection requirements and to ensure good quality image. In order to optimize the diagnostic image quality, optimizing the dose to the patient, a careful activity determination must be achieved using a dose calibrator. A radionuclide activity calibrator is in essence a well-type gas-filled ionization chamber into which a radioactive material is introduced for measurement. The activity of the material is measured in terms of the ionization current produced by the emitted radiations that interact within the gas. The chamber is usually sealed and under pressure, and has two coaxial cylindrical electrodes maintained at a voltage difference from a suitable supply in the nuclear medicine environment, the range of activities to be measured with an accuracy of $\pm 5 \%$ or better will typically be between $1 \mathrm{MBq}$ and $10 \mathrm{GBq}$ (Mo et al., 2006; Ceccatelli et al., 2007; Wurdiyanto et al., 2012).

Several quality control tests are necessary to ensure the proper operation of the dose calibrators, among which the tests for the linearity of the response, accuracy, precision, and physical functioning of the instrument are vital (Zeinali, 2010). The linearity of the response test confirms the ability of the instrument to measure a range of low to high activity doses with a required degree of accuracy. It is important that the linearity of the response of the dose calibrator to be ascertained over the range of its use between the maximum activity administered and $1 \mathrm{MBq}$. It has been recommended that the test to be carried out upon acceptance, repair, and then annually. This test is mostly carried out by measuring a high activity, short-lived radionuclide for a given period of time by the instrument. Tc$99 \mathrm{~m}$ is used for this purpose. Accuracy is a quality control measure performed upon acceptance, repair, and then annually, to ensure that the activity values determined by the dose calibrator are traceable to national or international standards of radioactivity within the indicated uncertainties (Zeinali, 2010; Santos et al., 2009). Precision test is also essential to verify the random uncertainty of the dose calibrators. It has been recommended that the test to be carried out upon acceptance, repair, and then annually. This test is mostly carried out by measuring a high activity, shortlived radionuclide for a given period of time by the instrument. In most countries, the regulation suggests that the administered activity should be within $10 \%$ of the prescribed one, what is attained with a radionuclide calibrator accuracy of $\pm 5 \%$ (IAEA, 2008) (recommended by IAEA, whereas American National Standards Institute (ANSI) recommended accuracy of $\pm 10 \%$ (Zanzonico, 2008). In AAPM Report No. 181, the task group recommended that the assayed dosage be within $\pm 10 \%$ of the prescribed one for diagnostic and $\pm 5 \%$ for therapeutic (IAEA, 1984; ICRP, 2008, Nichols, 2206 Calhoun et al., 1987) Results from this study are intended to assist in efforts towards improving the quality of nuclear medicine practices.

\section{Material and Methods:-}

Two dose calibrators under investigations (shown in Fig-1.) were manufactured by the Capintec, Inc. (Model no. CRC 25R) and Veenstra (model no. VDC 404). The following QC tests were performed for the acceptance of this two dose calibrator (Capentec, 2007). Zero background check, Accuracy \& precision check, constancy check, linearity check, geometry effects and volume dependency check.

To perform the above tests a standard Cesium-137 source is used. For linearity and volume dependency check it has beed used Tc-99m and I-131.

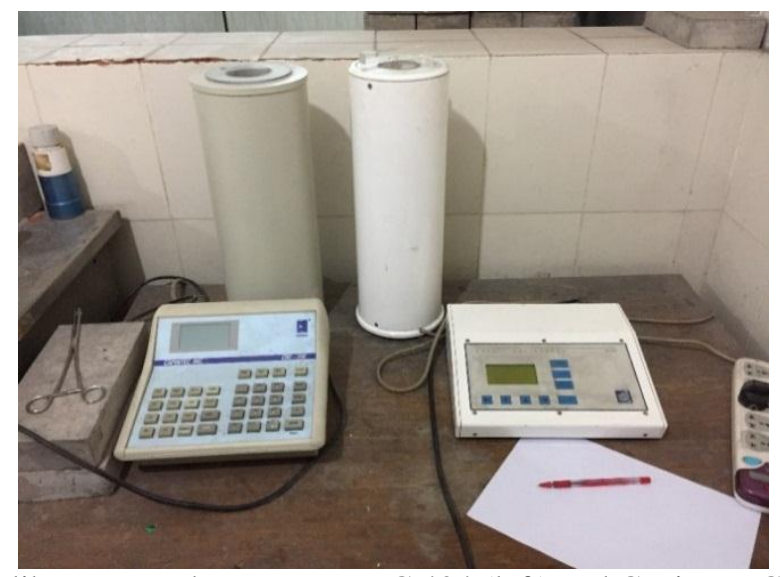

Fig 1:-Dose Calibrators used Veenstra VDC 404 (left) and Capintec. CRC 25R (right) 


\section{Zero adjustment:}

Zero adjustment balanced for any non-ideal characteristics of the electronic measuring system of the radionuclide dose calibrator. The system should be set zero when it is put in to service, when the measurement conditions change or after considerable changes in temperature. Zero adjustment is performed according the manufacturers specification for these instruments. This time is measured for both detectors by using Tc-99m and I-131 source. Measurements were repeated for three times for each and considered average values.

\section{Linearity check:}

The intention of this test is to investigate the linearity of the activity response of a radionuclide calibrator over the range of activities for which it is to be used. There are two methods for this test, Decaying source method and Graded sources method. It has been recommended that the test to be carried out upon acceptance, repair, and then annually. This test is done using a vial or syringe of a radioactive sample whose activity is at least as large as the maximum activity normally assayed in a prepared radio pharmaceutical kit, in a unit dosage syringe, or in a radio pharmaceutical therapy, whichever is largest. For the linearity check, a Tc-99m source was used. The activity was measured at regular intervals for first 7 hours.

\section{Accuracy:}

Accuracy is a quality control measure performed upon acceptance, repair, and then annually, to ensure that the activity values determined by the dose calibrator are traceable to national or international standards of radioactivity within the indicated uncertainties. The accuracy of a measurement is determined by how close it is to the true value. The Cesium source is placed into the source holder by means of the remote handling device and the source holder is induced into the calibrator.The steps repeated for 15 times. To observe accuracy percentage difference between average activity and actual activity is determined by using the following equation,

Accuracy percentage $=\frac{\text { Actual Activity }- \text { Measured Activity }}{\text { Actual Activity }} \times 100 \%$

All these steps are repeated for both calibrators.

\section{Precision:}

Precision is a measure of the spread of values obtained from a sequence of measurements. It is usually defined in terms of the standard deviation of a set of 10 consecutive measurements. Precision test is to confirm that the random uncertainty of a single measurement is primarily determined by the random nature of radioactive decay. A larger than expected value indicates the possible presence of another random source of uncertainty that had not been anticipated. The recommended values for the above quality control measures are within \pm 5 to $10 \%$, depending on the radionuclide of interest and measurement conditions.

\section{Constancy:}

Constancy means reproducibility in measuring the activity of a known source over a long period of time. The dose calibrator is required to be checked for constancy with a dedicated check source at the beginning of each day of use (Suhaib et al., 2016). This includes weekends and holidays, if radiopharmaceuticals are administered to a patient. Day to day readings should agree to within $10 \%$ percent error or better and should be recorded daily. If there is greater than the $10 \%$ error the unit must either be repaired or replaced. To check the constancy test of the dose calibrator the patient dosages were measured several times before administration to the patient. Records were reviewed and the true activity was calculated with decay correction (Capintec, 2007; Nichols et al., 2006; AAPM, 2012).

\section{Geometry Test:}

A point source of Tc-99m in a syringe was measured at various depth positions in the dose calibrator to see how the activity varies with the different depth of the dose calibrator. The source is taken in a vial. It is attached at different points. Height of the vail is measured. At each height activity is measured. Three readings are taken at each point average activity was calculated. By using these readings activity against distance graph is produced for each syringe.

\section{Volume dependency check:}

For the volume dependency effects, Tc-99m source is used. A solution of Tc-99m is taken in a $1 \mathrm{ml}$ syringe. Initial volume of the radioactive sample is $0.8 \mathrm{ml}$. Background count is determined. Activity of the source is measured. Actual activity is determined by subtracting the background count. Volume of the sample is gradually increased by 
adding saline water. For each volume activity is calculated. These measurements are repeated for $3 \mathrm{ml}$ and $5 \mathrm{ml}$ syringe.

\section{Response Time:}

The response time is measured to determine the time taken by the calibrator to give a stable reading. After every measurement it takes a small time to return to zero reading state. This time is measured to estimate the frequency of measurement. These tests are essential to ensure appropriate dose for each individual patient. Thus the patients receive required does for treatment or diagnosis and it is also possible to prevent the side effects of excessive dose. Stop watch is used to measure the time taken to give a stable reading. Measurements are repeated for both calibrators and average response times for both sources are measured. To compare the shielding, background count is measured by the both calibrator simultaneously. These measurements are repeated for both calibrator and average background count is compared.

\section{Results and Discussion:-}

Zero return time test

Table 1:-Data for Zero Return Time of Capintec $\mathrm{CRC}^{\circledR}-25 \mathrm{R}$ Dose Calibrator

\begin{tabular}{|c|c|c|c|}
\hline Trial no. & Time (minutes) & Trial no. & Time (minutes) \\
\hline 1 & 3.34 & 1 & 5.21 \\
\hline 2 & 3.25 & 2 & 5.06 \\
\hline 3 & 3.39 & 3 & 5.18 \\
\hline 4 & 3.31 & 4 & 5.27 \\
\hline 5 & 3.28 & 5 & 5.13 \\
\hline Average & 3.31 & Average & 5.17 \\
\hline
\end{tabular}

Table 2:-Data for Zero Return Time of Veenstra VDC-404 Dose Calibrator

\begin{tabular}{|c|c|c|c|}
\hline For Tc-99m & For I-131 & Time (minutes) \\
\hline Trial no. & Time (minutes) & Trial no. & 5.67 \\
\hline 1 & 3.98 & 1 & 5.82 \\
\hline 2 & 3.83 & 2 & 5.72 \\
\hline 3 & 3.79 & 3 & 5.65 \\
\hline 4 & 3.88 & 4 & 5.81 \\
\hline 5 & 3.94 & 5 & 5.73 \\
\hline Average & 3.88 & Average & \\
\hline
\end{tabular}

Data shows in Table 1 and 2 that zero return time for Capintec CRC-25R is smaller than Veenstra VDC-404 Dose calibrator. It also depends on the isotope. For Iodine-131 zero return time is larger than Te-99m. In practical, Veenstra VDC-404 gave a small up to a long time of the removal of the source. This given is above table is the time taken to trop of activity below $1 \mu \mathrm{Ci}$. 


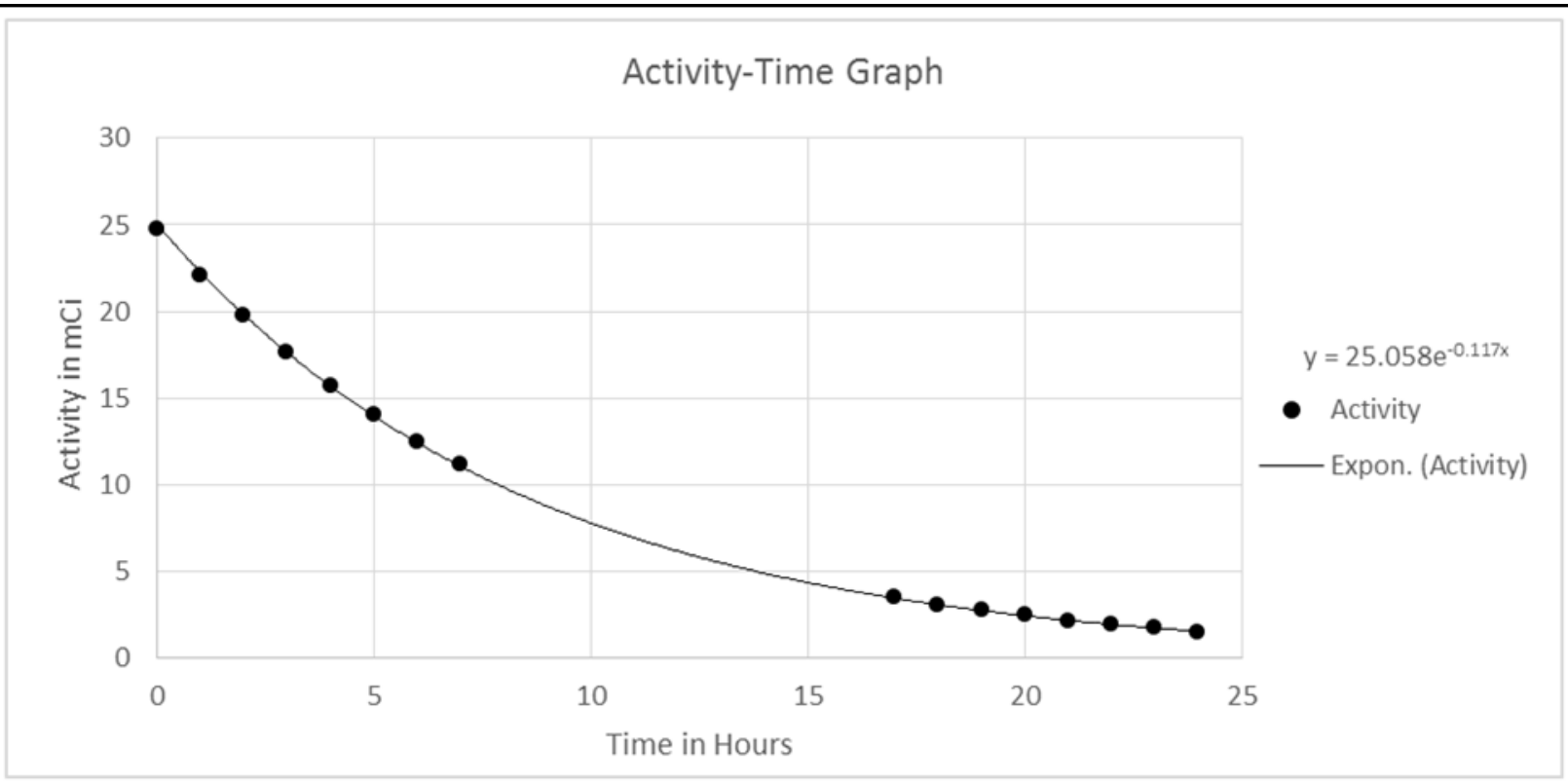

Fig 2:-Activity-Time graph (Tc-99m) measured by of Capintec CRC ${ }^{\circledR}-25 R$ Dose Calibrator

Fig-2. shows the exponential decay of radioactive samples. Measurements were made at hourly intervals for 7 hours. The next measurement was taken the next day at 9:30 am on next day and subsequent measurements were taken again at hourly intervals. Using regression model, the equation of best fit was found to be $y=25.058 e^{-0.117 x}$.

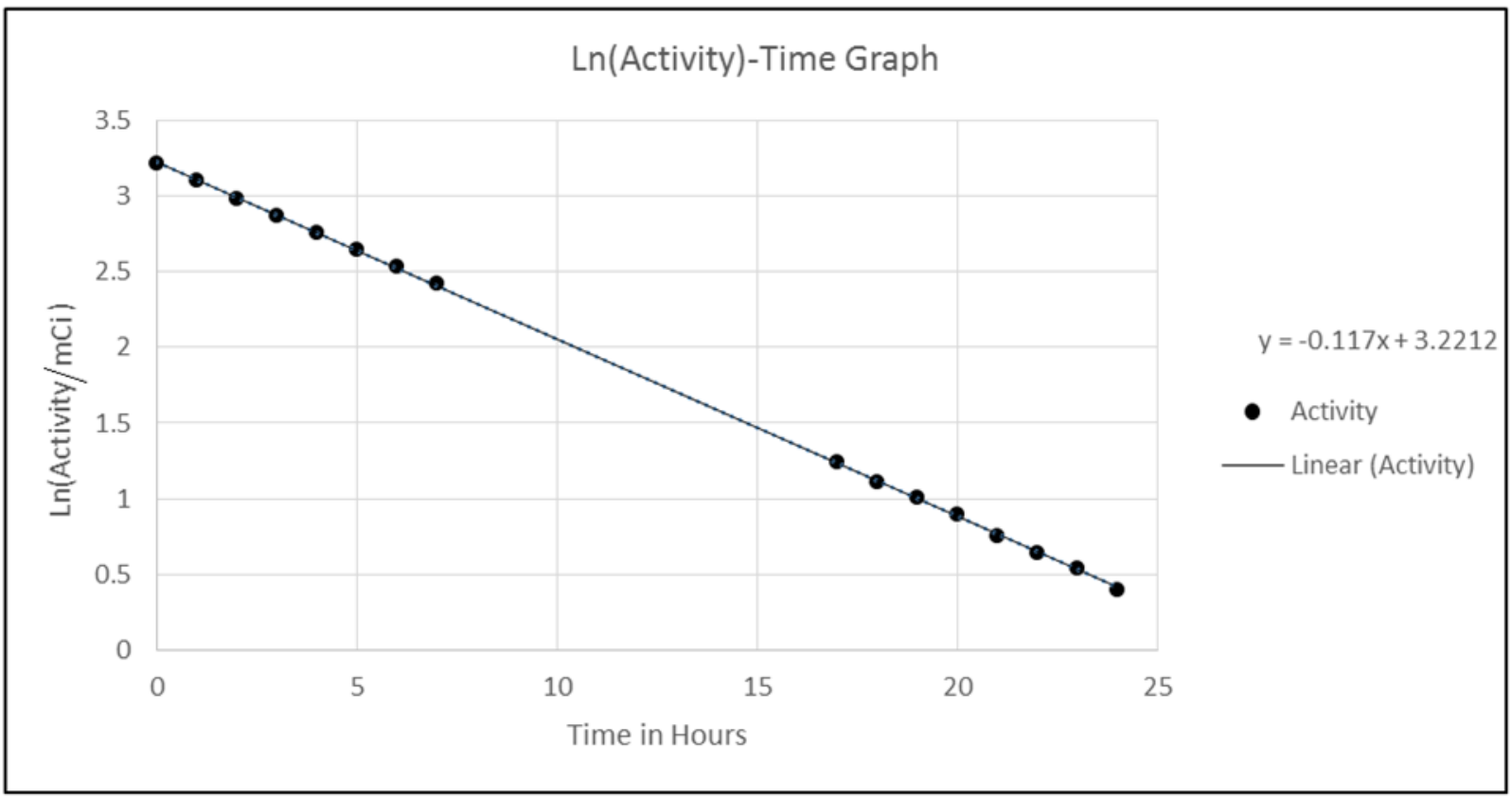

Fig 3:-Ln(Activity)-Time graph (Tc-99m) measured by of Capintec CRC ${ }^{\circledR}-25 R$ Dose Calibrator

Fig-3. shows the plot of the natural log of the activity versus time in hours. From the graph it was found the half-life 5.92 using decay constant, $\lambda=0.117$ hour $^{-1}$ that was very close the actual value of the half life of Tc- $99 \mathrm{~m}$. Percentage difference between measured and actual value was found $1.5 \%$. 


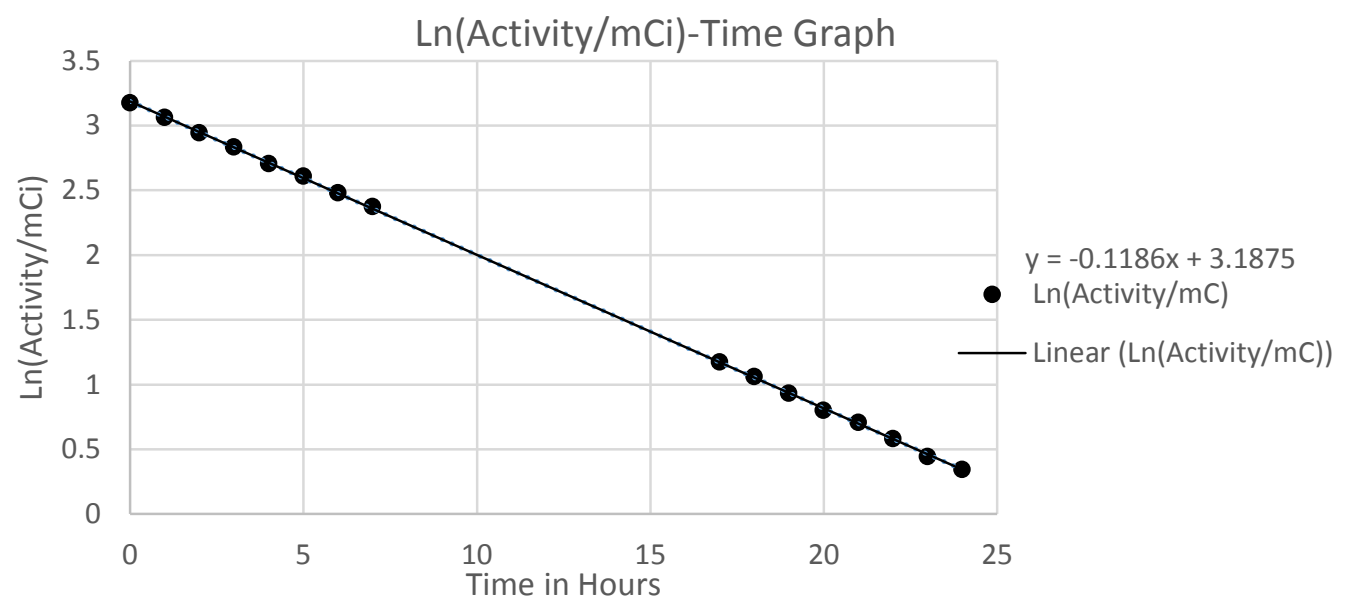

Fig 4:-Ln(Activity)-Time graph (Tc-99m) measured by of Veenstra-404 Dose Calibrator

Fig-4. shows the exponential decay of sample of Tc-99m measured using a Veenstra - 404 Dose Calibrator. Measurements were made at hourly intervals for 7 hours same as before. Here also found the value of half-life 5.90 hours where as the actual half life of Tc- $99 \mathrm{~m}$ is 6.01 hours. In both cases the measured and actual value are well fitted with expected values.

\section{Geometry Test}

A point source of Tc-99m in a syringe was measured at various depth positions in the dose calibrator to see how the activity varies with the different depth of the dose calibrator. The source is taken in a glass vial. It was placed at different depth positions of the dose calibrators. Height of the vial position was recorded. At each height activity is measured. Three readings are taken at each point average activity was calculated. By using these readings activity against distance graph is produced for each syringe.

\section{Activity-Distance Graph}

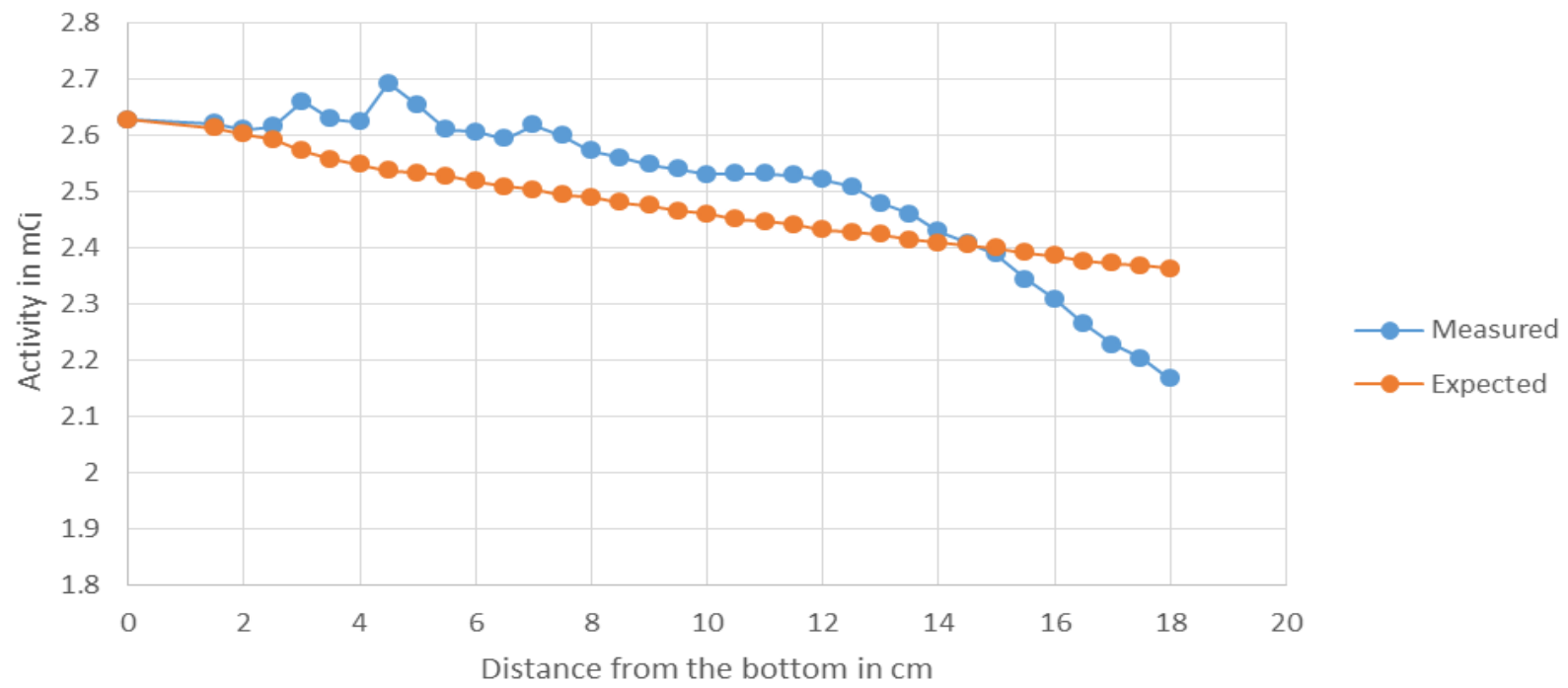

Fig 5:-Activity-Position graph measured by of Capintec CRC $^{(\circledast)}-25 R$ Dose Calibrator

Fig-5. shows that the height of the vial is gradually increased from the bottom of the calibrator and activity is measured. Up to $2.5 \mathrm{~cm}$ measured and expected readings are almost equal. After that there is a difference between 
two readings and the measured value remains larger till $14 \mathrm{~cm}$ height. After that measured activity becomes smaller than the expected value.

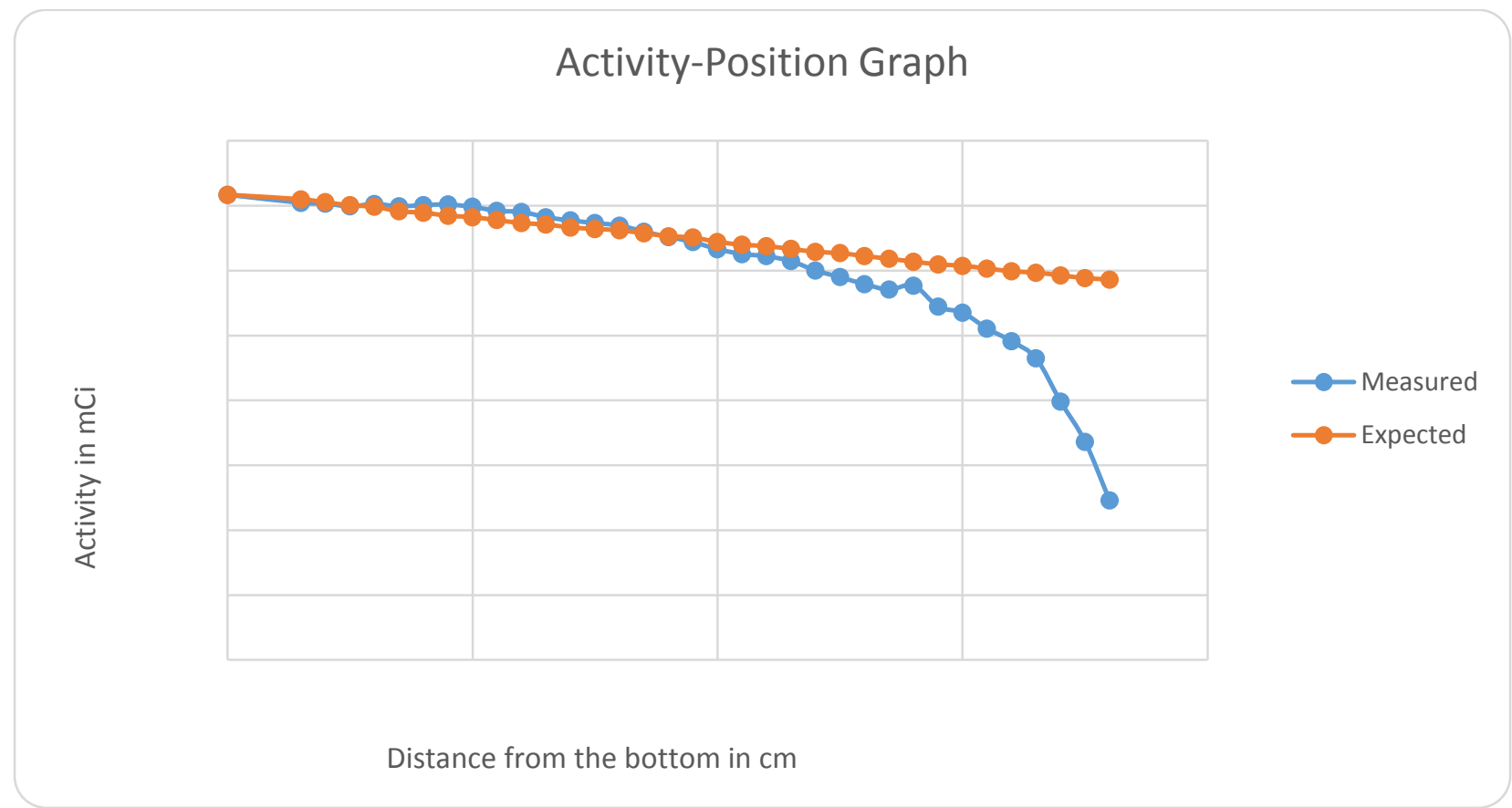

Fig 6:-Activity-Position graph measured by of Veenstra-404 Dose Calibrator

Fig-6 shows that expected values and measured values agreed closely for distances up to $12 \mathrm{~cm}$ after which they started to deviate. Increasing the distance exponentially increased the deviation.

\section{Constancy test:}

Activity at Different Day of Measurement

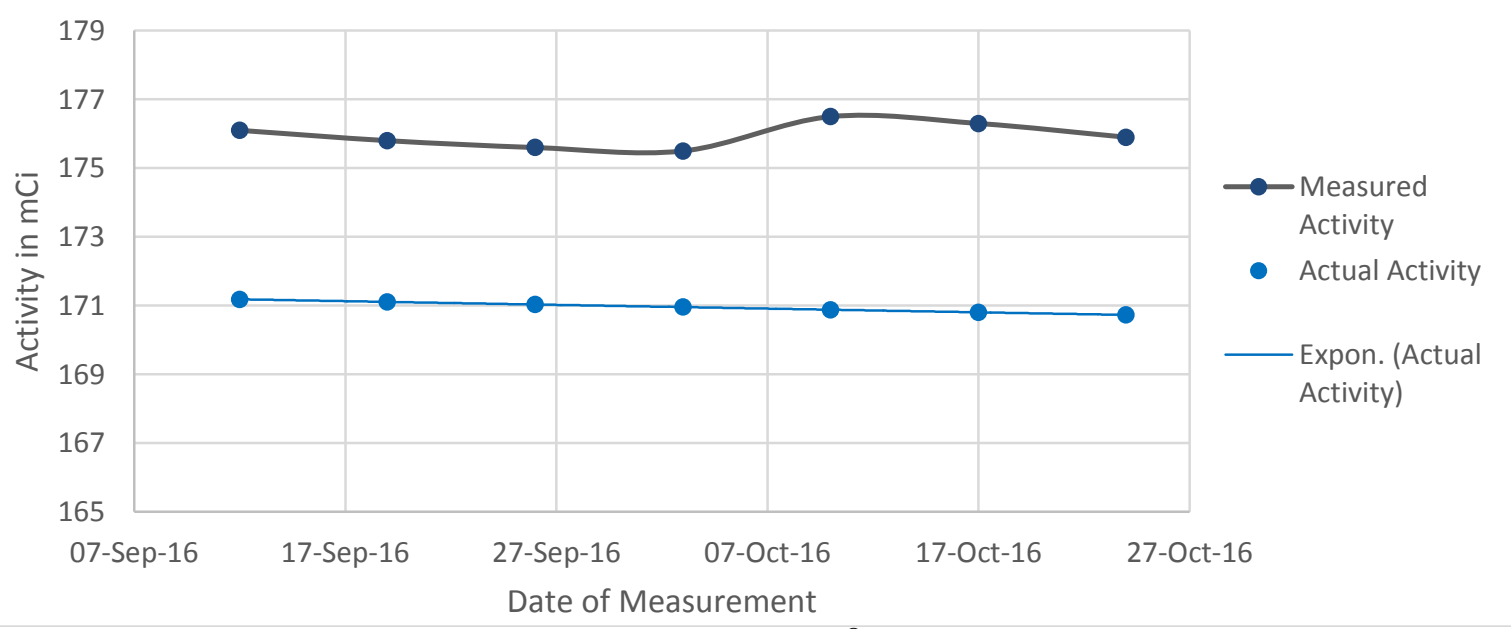

Fig 7:-Activity-Time for Capintec $\mathrm{CRC}^{\circledR}$-25R Dose Calibrator

Fig. 3.11 shows constancy of the reading within 5\%. In actual activity should decrease with time but there is rise in activity between $3^{\text {rd }}$ and $10^{\text {th }}$ October, 2016. It might be due to contamination of the chamber because after that readings decrease following exponential decay. 


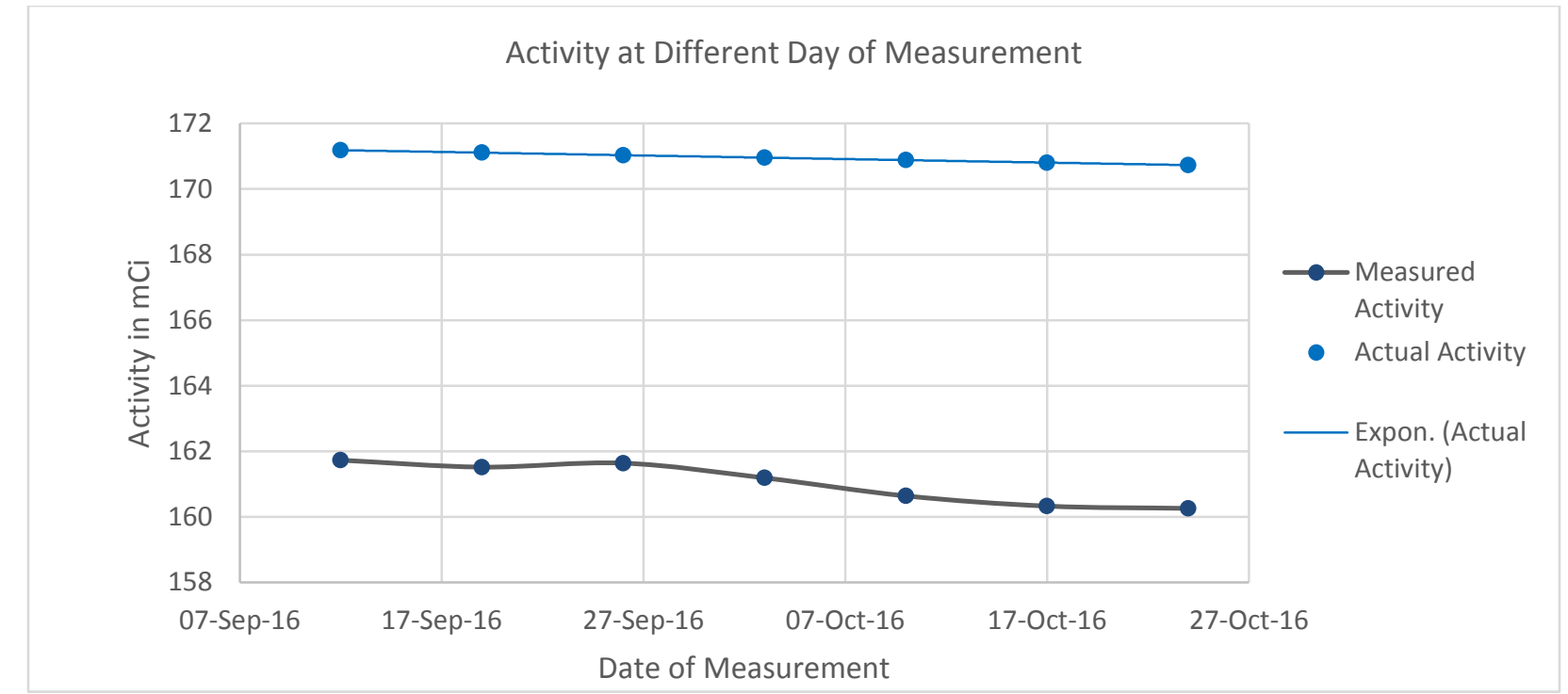

Fig 8:-Activity-Time for Veenstra-404 Dose Calibrator

Fig-8. Shows constancy of the reading within 5\%. There is some fluctuations in the activities which might be produced due to random error bot there is an overall exponential decay.

\section{Geometry Test}

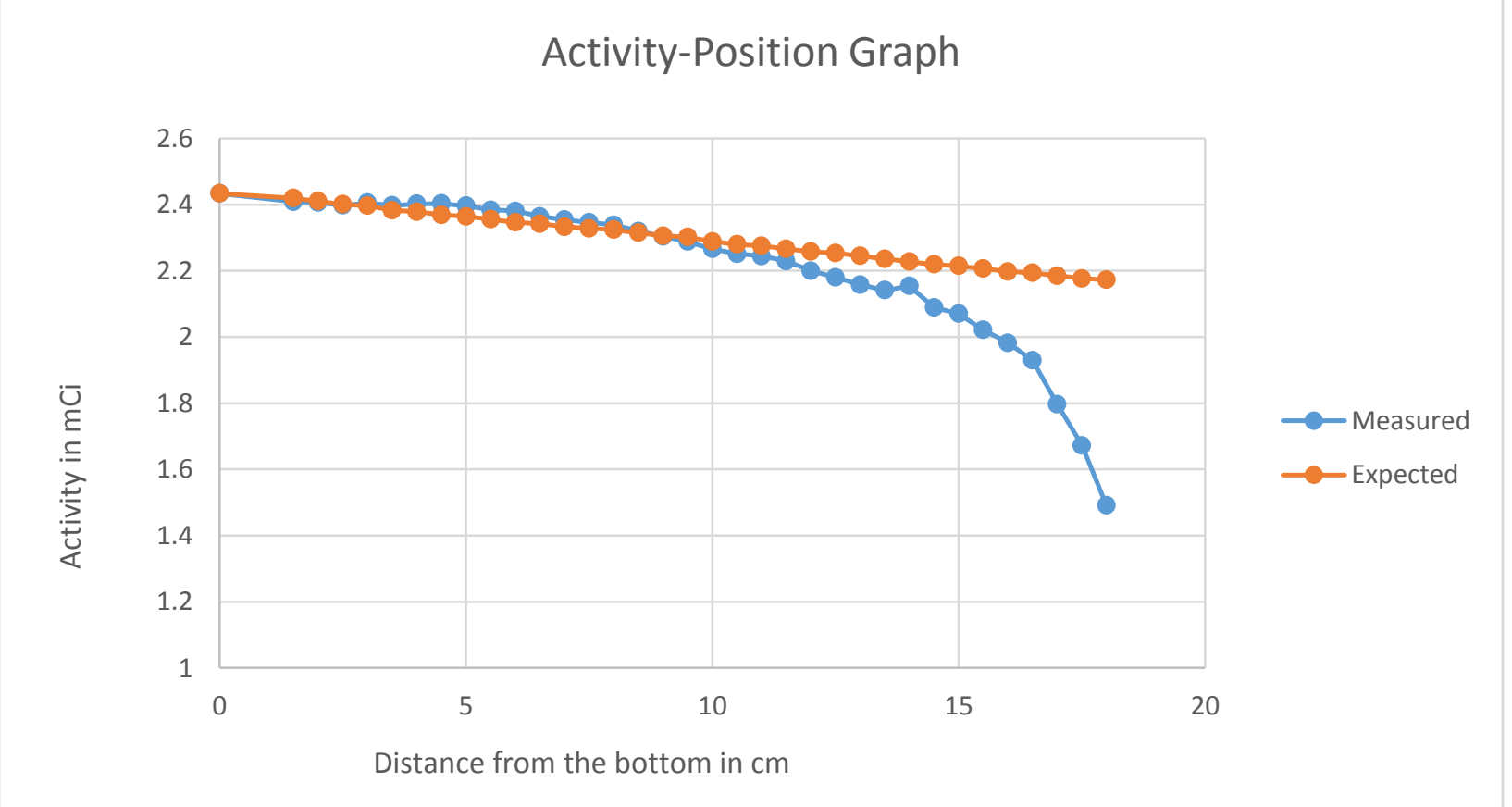

Fig 9:-Activity-Position graph measured by of Capintec $\mathrm{CRC}^{\circledR}-25 \mathrm{R}$ Dose Calibrator

Fig-9. shows that the height of the vial is gradually increased from the bottom of the calibrator and activity is measured. Up to $2.5 \mathrm{~cm}$ measured and expected readings are almost equal. After that there is a difference between two readings and the measured value remains larger till $14 \mathrm{~cm}$ height. After that measured activity becomes smaller than the expected value. 


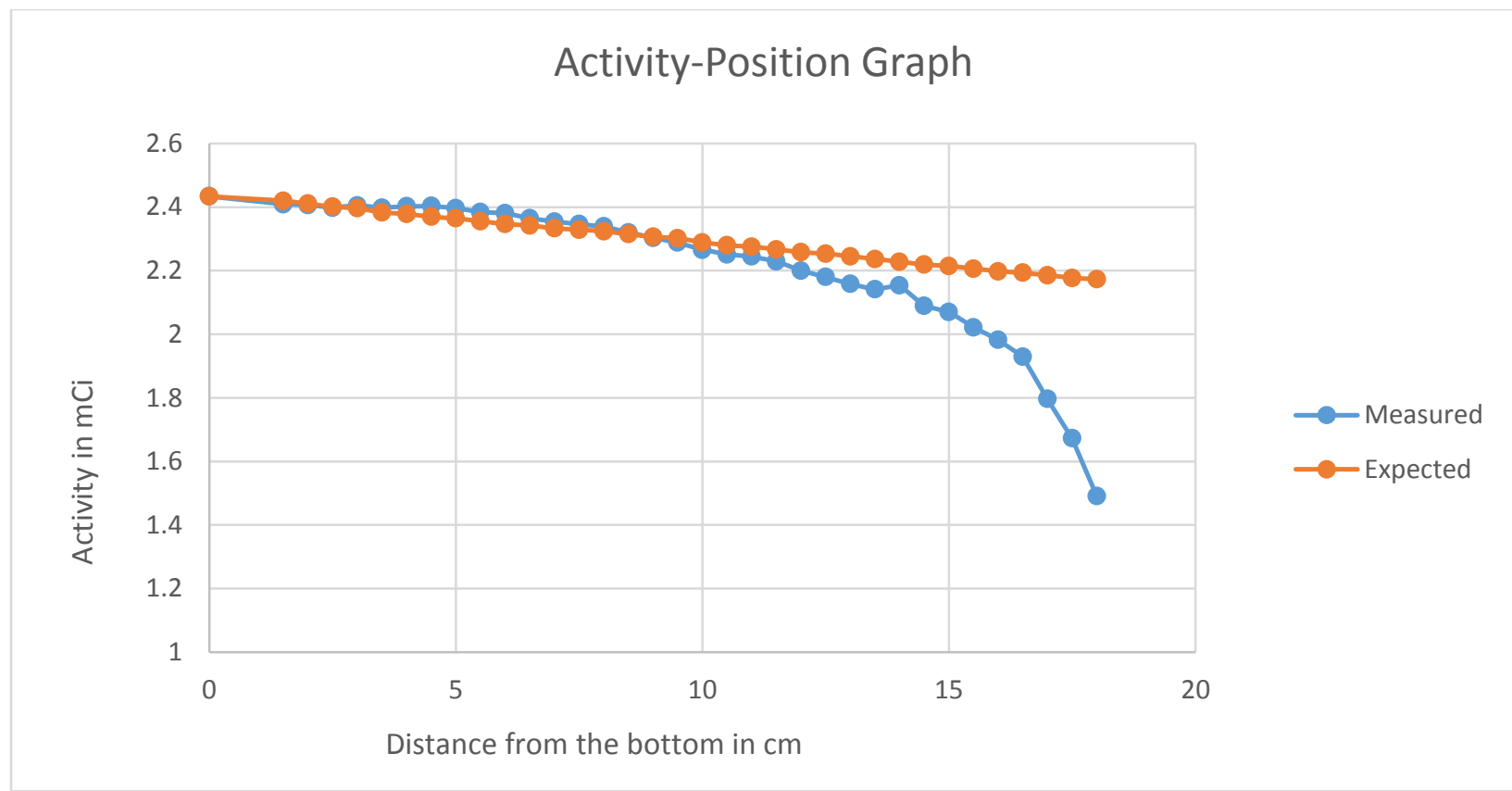

Fig 10:-Activity-Position graph measured by of Capintec $\mathrm{CRC}^{\circledR}-25 \mathrm{R}$ Dose Calibrator

Fig-10. shows that expected values and measured values agreed closely for distances up to $12 \mathrm{~cm}$ after which they started to deviate. Increasing the distance exponentially increased the deviation.

\section{Volume test}

For the volume dependency effects, Tc-99m source is used. A solution of Tc-99m is taken in a $1 \mathrm{ml}$ syringe. Initial volume of the radioactive sample is $0.8 \mathrm{ml}$. Background count is determined. Activity of the source is measured. Actual activity is determined by subtracting the background count. Volume of the sample is gradually increased by adding saline water. For each volume activity is calculated. These measurements are repeated for $3 \mathrm{ml}$ and $5 \mathrm{ml}$ syringe.

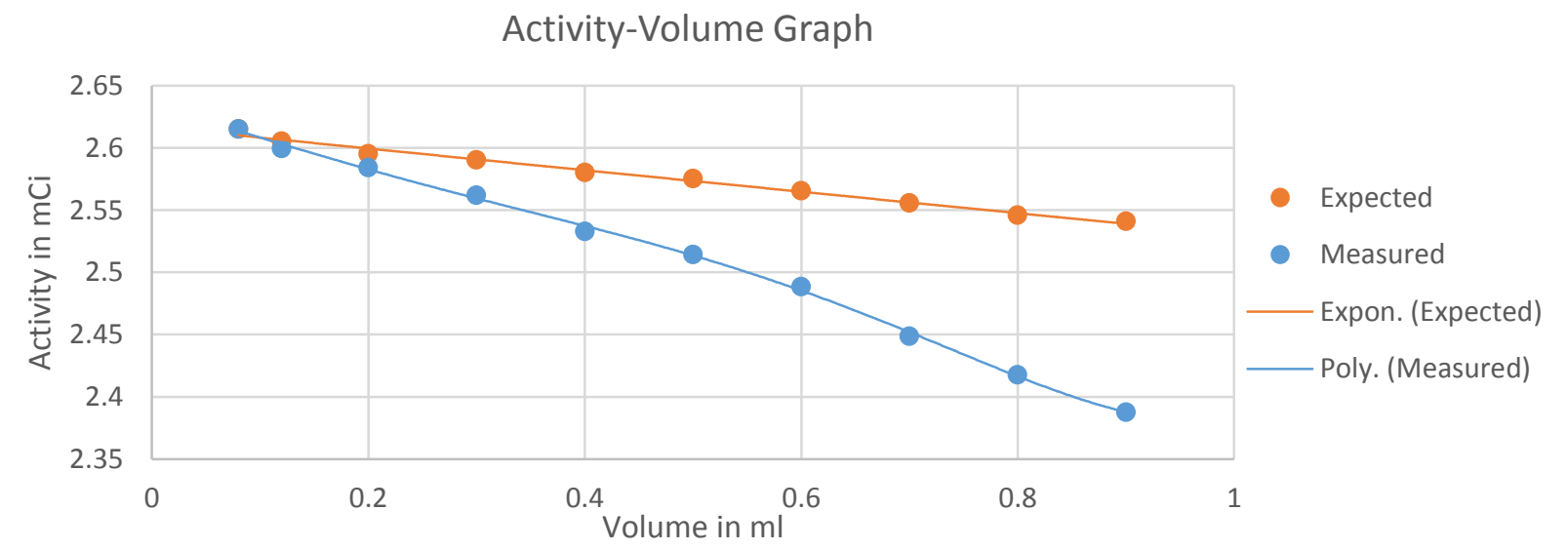

Fig 11:-Activity-Volume graph (1 ml Syringe) measured by of Capintec CRC ${ }^{\circledR}-25 R$ Dose Calibrator

Fig-11. shows the deviation of expected and measured values of activity for volumes of Technitium-99 dose samples which were taken in $1 \mathrm{ml}$ syringes. As larger volumes were tested, the results deviated more from the expected results. The largest deviation shown on the graph is $0.1 \mathrm{mCi}$ at $0.7 \mathrm{ml}$ 


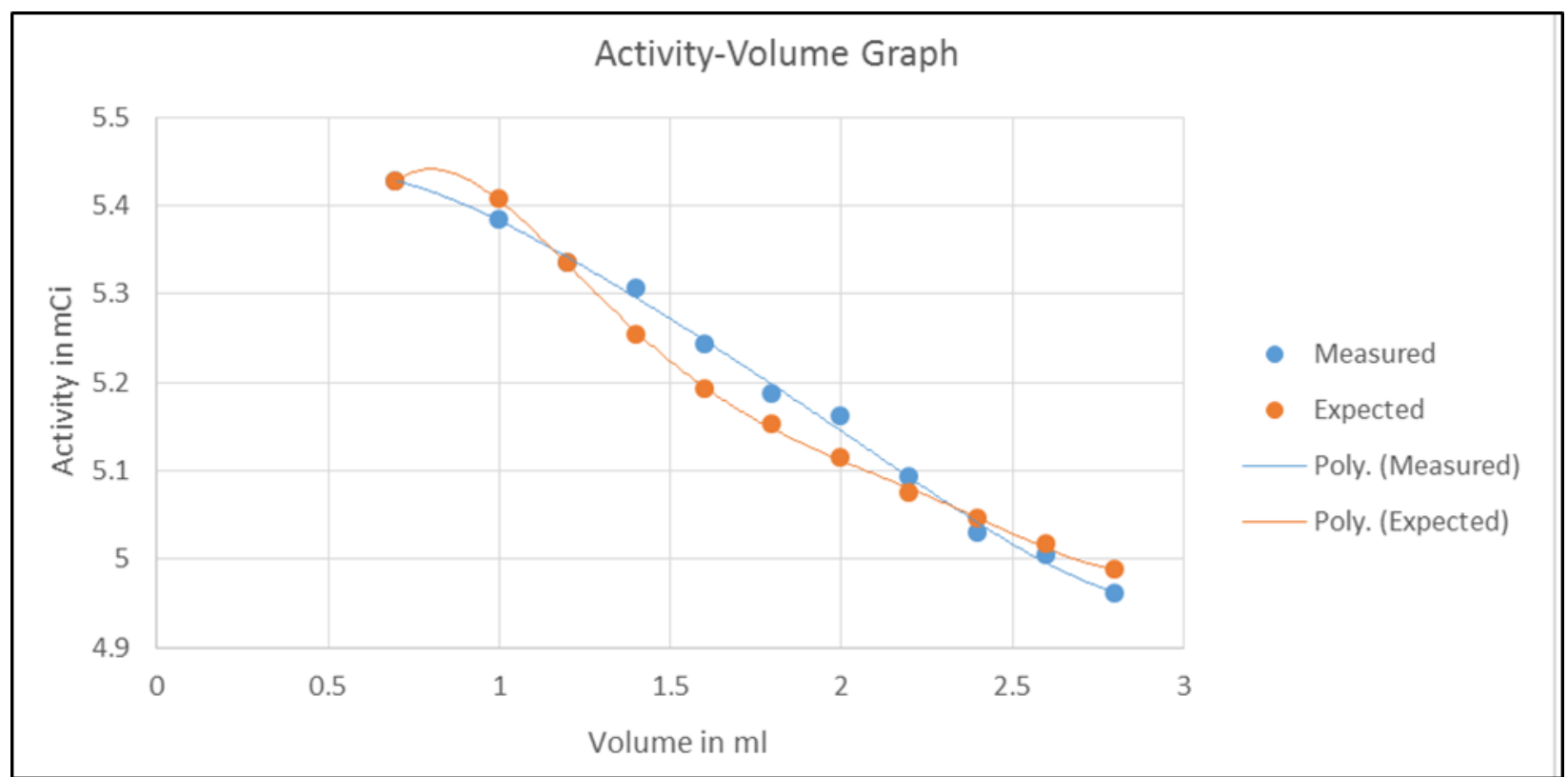

Fig 12:-Activity-Volume graph ( $3 \mathrm{ml}$ Syringe) measured by of Capintec $\mathrm{CRC}^{\circledR}-25 \mathrm{R}$ Dose Calibrator

Fig-12 shows the deviation of expected and measured values of activity for volumes of Technitium-99 dose samples which were taken in $3 \mathrm{ml}$ syringes. Here the measured values are seen to fall within a straight line which intersects the line of expected values at 3 points. For most of the data points, the measured value is higher than expected. The largest deviation, which was $0.04 \mathrm{mCi}$, was recorded at a volume of $1.8 \mathrm{ml}$

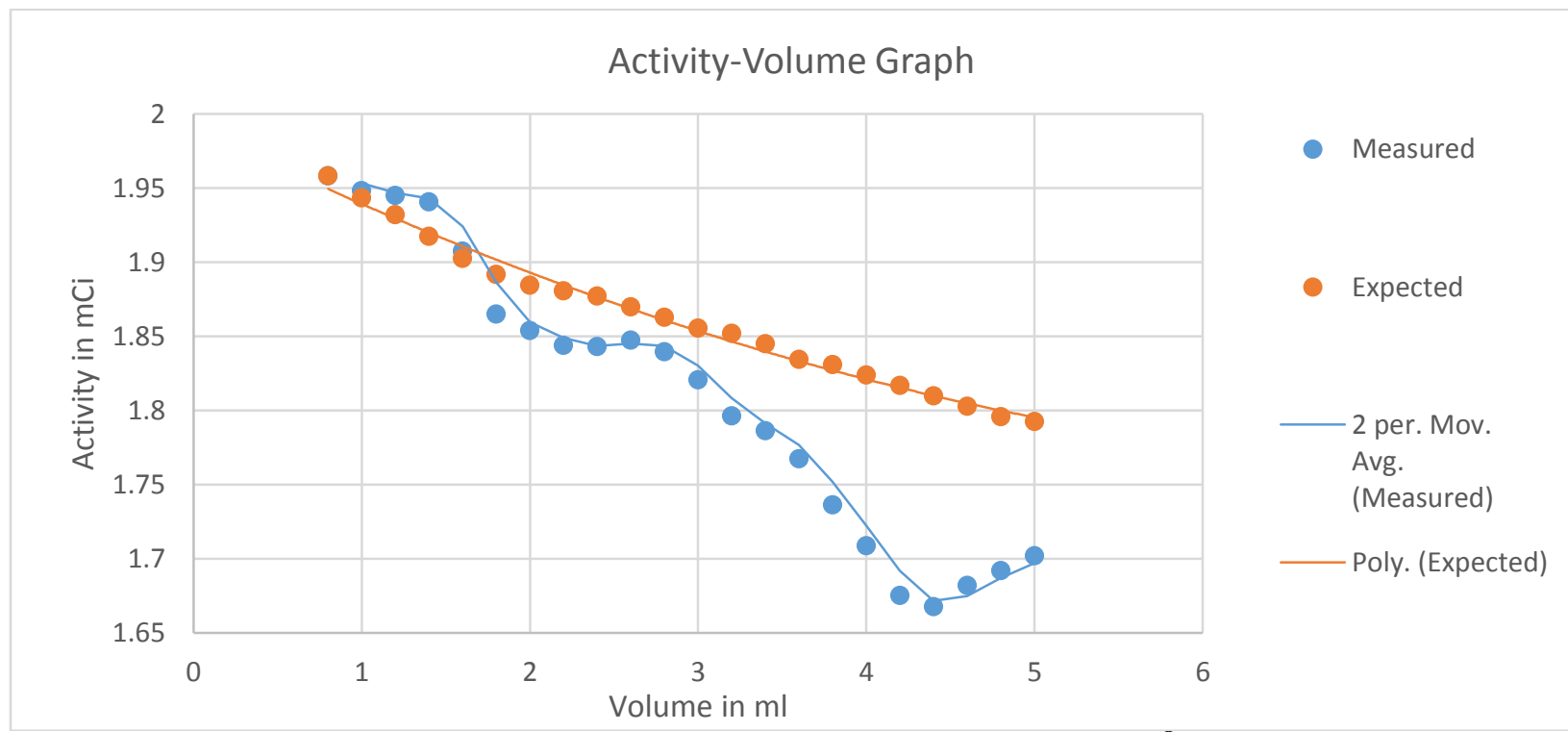

Fig 13:-Activity-Volume graph (5 ml Syringe) measured by of Capintec CRC ${ }^{\circledR}-25 R$ Dose Calibrator

Fig-13. shows the deviation of expected and measured values of activity for volumes of Technitium-99 dose samples which were taken in $5 \mathrm{ml}$ syringes. Here the measured values are seen to be spread our more than previous test. For volumes between 1 and $2.5 \mathrm{ml}$, the measured values are within $+/-0.05 \mathrm{mCi}$ of the expected values, but for larger volumes, the deviations increases reaching a maximum of $0.133 \mathrm{mC}$ i at a volume of $4.4 \mathrm{ml}$.

In case of $1 \mathrm{ml}$ syringe, difference between measured activity and expected activity gradually increases with increasing volume. Most prominent difference is observed at largest volume. Data of $3 \mathrm{ml}$ syringe shows very little 
difference between measured and actual activity. In case of $5 \mathrm{ml}$ syringe, the difference between measured and actual activity changes in random manner and it is largest at $4.4 \mathrm{ml}$. After that activity increases and difference slightly decreases.

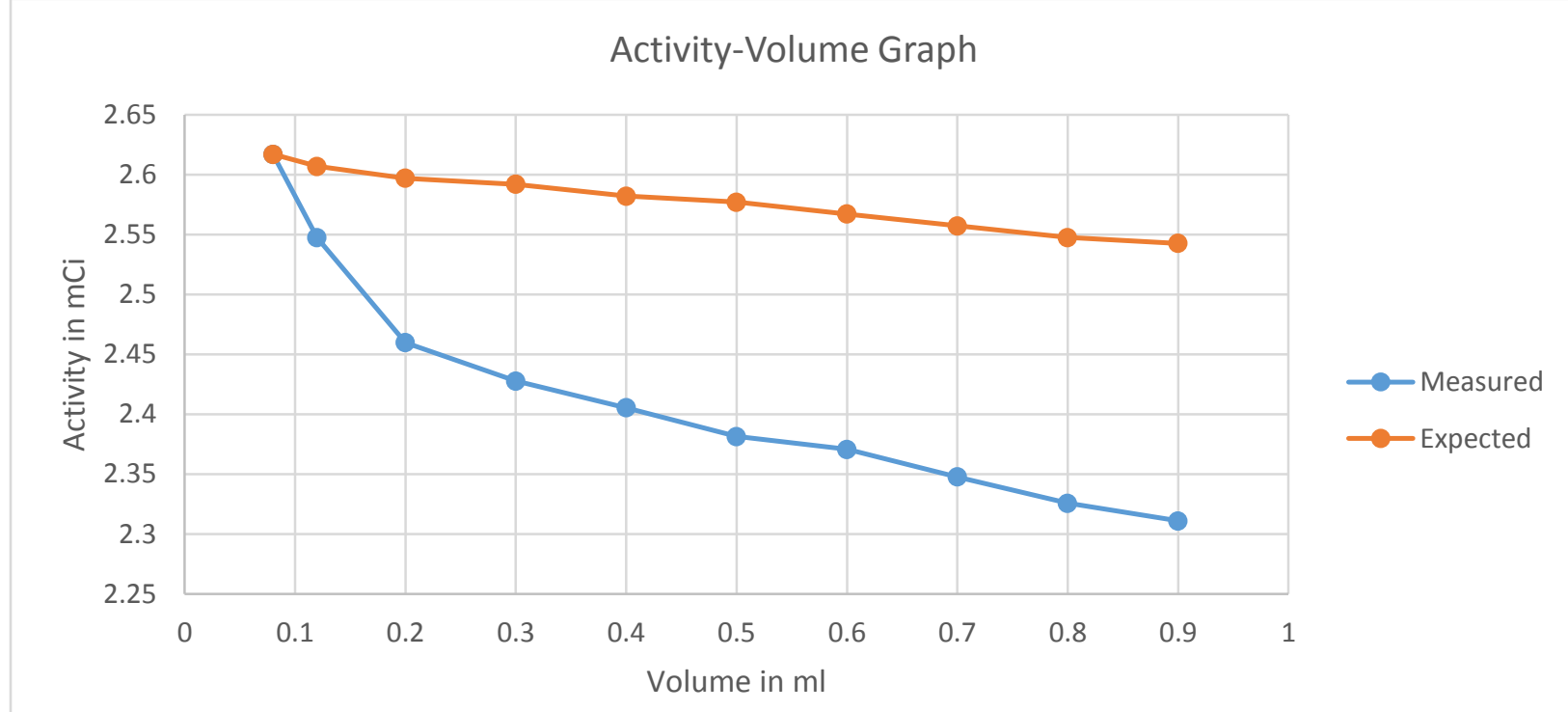

Fig 14:-Activity-Volume graph (1 ml Syringe) measured by of Veenstra-404 Dose Calibrator

Fig-14. shows the deviation of expected and measured values of activity for volumes of Technitium-99 dose samples which taken in $1 \mathrm{ml}$ syringes. The graph shows that there is a significant difference between expected and measured values, deviating almost immediately beyond a volume of $0.1 \mathrm{ml}$. The largest deviation observed was at $0.9 \mathrm{ml}$, which was equal to $0.15 \mathrm{mCi}$.

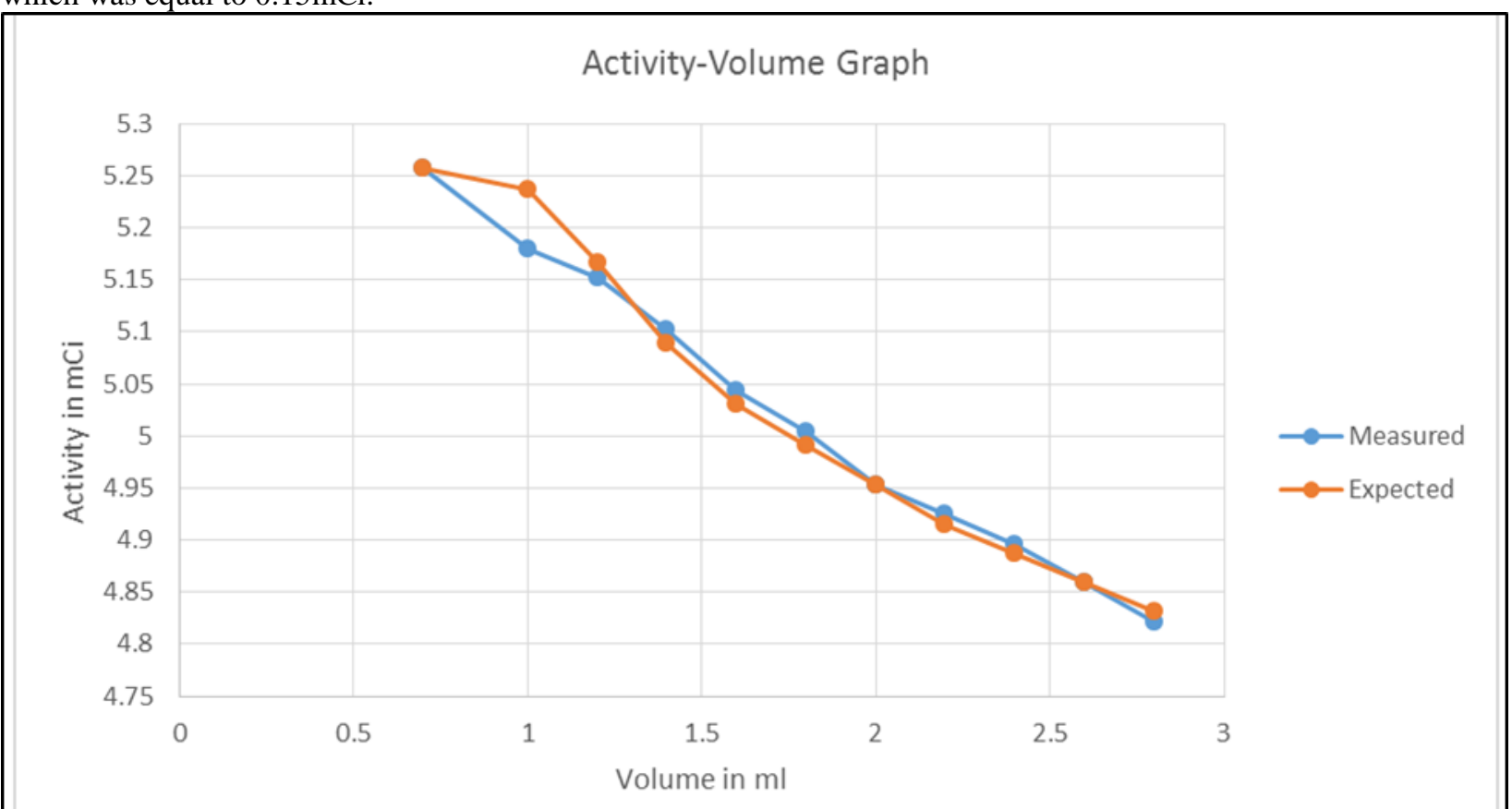

Fig 15:-Activity-Volume graph ( $3 \mathrm{ml}$ Syringe) measured by of Veenstra-404 Dose Calibrator

Fig-15. shows the deviation of expected and measured values of activity for volumes of Technitium-99 dose samples which were taken in $3 \mathrm{ml}$ syringes. The graph shows that for volumes between 1.25 and $3 \mathrm{ml}$, the expected and measured values are nearly equal. There is only a slight discrepancy in the values for the measurement at $1 \mathrm{ml}$. 


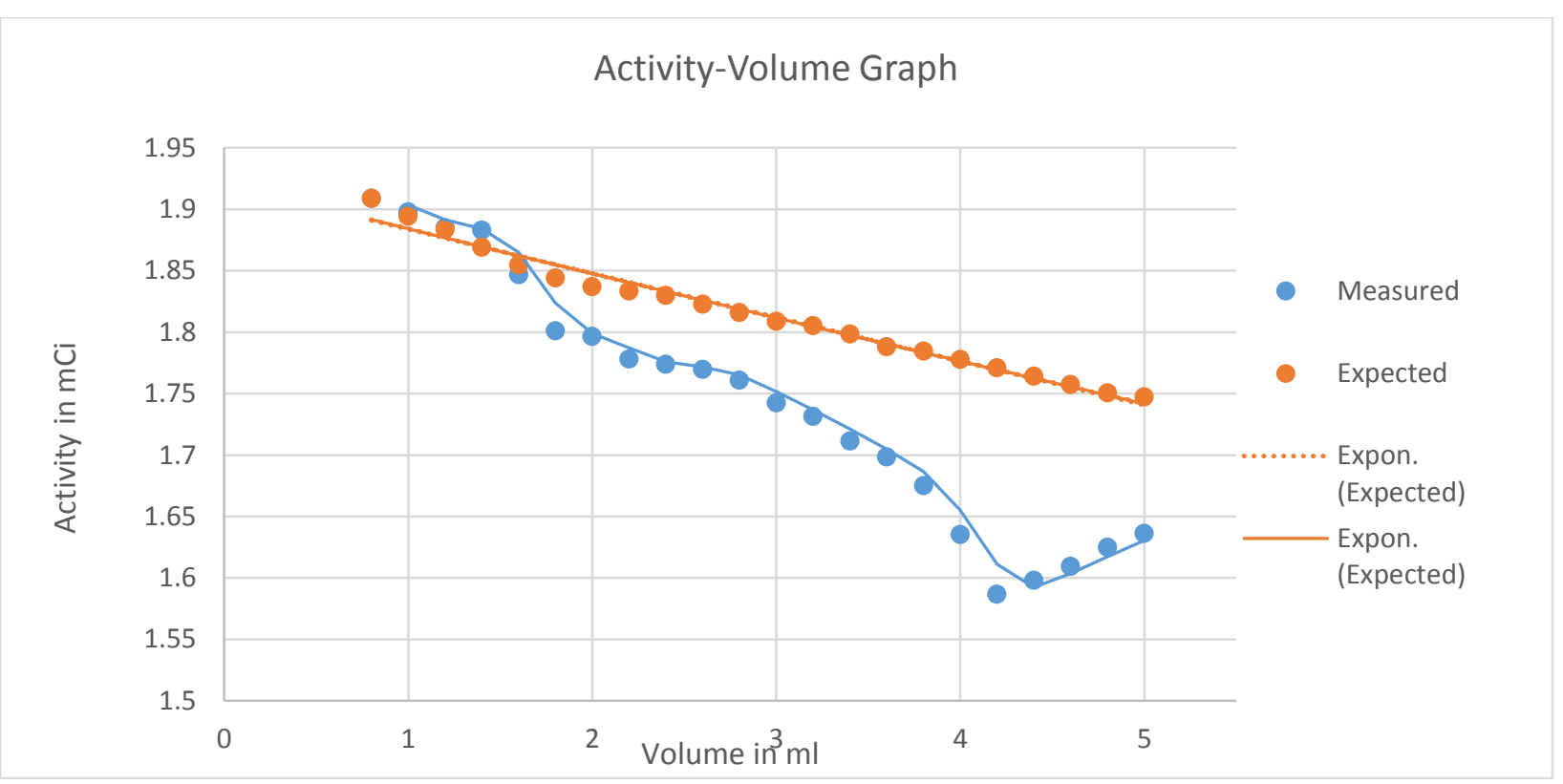

Fig 16:-Activity-Volume graph ( $5 \mathrm{ml}$ Syringe) measured by of Veenstra-404 Dose Calibrator

Fig-16 shows the deviation of expected and measured values of activity for volumes of Technitium-99 dose samples which were taken in $5 \mathrm{ml}$ syringes. The results obtained are similar to that obtained for the Capintec $\mathrm{CRC}^{\circledR}-25 \mathrm{R}$ Dose Calibrator where measured values differed from expected ones beyond $2 \mathrm{ml}$. The largest difference was observed at $4.2 \mathrm{ml}$ which was equal to $0.27 \mathrm{mCi}$.

\section{Conclusions:-}

In our experience dose calibrators are highly reliable. When results of quality control procedures exceed the 5\% action levels, the uncertainty in the known value of reference sources and inattention to the details of the measurements can be the culprits. If the testing protocol has been designed to avoid the pitfalls, as described in this article, repeat testing and unnecessary repair can be avoided. When testing a dose calibrator, it is advisable to adopt an action level as low as possible. Otherwise, a dose calibrator that meets regulatory requirements can still contribute to problems. For example, the quality management program enforced by the NRC (Mo et al, 2006) requires the administration of certain radiopharmaceuticals to be within $10 \%$ of the prescribed dose. An apparent violation is possible if the measurements by the dose calibrator in the nuclear pharmacy and the dose calibrator in the clinic err in opposite directions, even though both dose calibrators are accurate to within $10 \%$. According to the findings of the study, it was found that all the tests performed at the INMAS, Dhaka were within the acceptable range and the dose calibrator used is of a good condition.

\section{References:-}

1. Calhoun, J.M.; Golas, D.B.; Harris, S.G., Effects of varying geometry on dosecalibrator response: Cobalt-57 and Technetium-99m, Journal of Nuclear Medicine, 28,1478-1483 (1987).

2. Capintec, Inc. Manual stock no. 9250-0122, rev. B - (August 2007), NJ 07446 , USA CRC-25R ${ }^{\circledR}$ Owner’s manual.

3. Ceccatelli, A., Benassi, M., D’Andrea, M., De Felice, P., Fazio, A., Nocentini, S., \& Strigari, L. (2007). Experimental determination of calibration settings of a commercially available radionuclide calibrator for various clinical measurement geometries and radionuclides. Applied radiation and isotopes, 65(1), 120-125.

4. IAEA (May 1991). Quality Control of Nuclear Medicine Instruments. International Atomic Energy Agency, Vienna, publication IAEA-TECDOC - 602 .

5. ICRP Publication 103, 2008. Recommendations of the ICRP, Annals of the ICRP,37.

6. Mo, L., Reinhard, M. I., Davies, J. B., Alexiev, D., \& Baldock, C. (2006). Calibration of the Capintec CRC712M dose calibrator for 18F. Applied radiation and isotopes, 64(4), 485-489.

7. Nichols KJ, Bacharach SL, Bergmann SR, et al. Instrumentation quality assurance and performance. J Nucl Cardiol. 2006;13:e25-e41. 
8. Report of AAPM (American Association of Physicists in Medicine) Task Group 181, June 2012

9. Santos, J. A. M., Carrasco, M. F., Lencart, J., \& Bastos, A. L. (2009). Syringe shape and positioning relative to efficiency volume inside dose calibrators and its role in nuclear medicine quality assurance programs. Applied Radiation and Isotopes, 67(6), 1104-1109.

10. Schrader, H., Kossert, K., \& Mintcheva, J. (2008). Calibration of a radionuclide calibrator system as a Bulgarian standard for activity. Applied Radiation and Isotopes, 66(6-7), 965-971.

11. Suhaib Alameen, Ahamed M. bdelfatah, Mubarak Almubarak, Assessment of Dose Calibrators Performance in Nuclear Medicine Department in Sudan, Sch. Acad. J. Pharm., June 2016; 5(6):245-250.

12. Wurdiyanto, G., Marsoem, P., Candra, H., \& Wijono, P. (2012). Radioactivity measurement of $18 \mathrm{~F}$ in $16 \mathrm{ml}$ vials for calibration of radionuclide calibrators. Applied Radiation and Isotopes, 70(9), 2237-2239.

13. Zanzonico, P. Routine Quality Control of Clinical Nuclear Medicine Instrumentation: A Brief Review. Journal of Nuclear Medicine. 2008; 49(7); 1114-1131

14. Zeinali, H. Z. (2010). An investigation on the performance of dose calibrators in nuclear medicine centers in Iran. Iranian Journal of Nuclear Medicine, 18(Supplement 1), 84. 